\title{
Does Mycophenolate Mofetil Increase the Risk of Cytomegalovirus Infection in Solid Organ Transplant Recipients? - A Mini-Review
}

\author{
Alice Tung Wan Song ${ }^{1}$, Edson Abdala ${ }^{1,2}$, \\ Patrícia Rodrigues Bonazzi ${ }^{1,2}$, Telésforo Bacchella ${ }^{2}$ and \\ Marcel Cerqueira César Machado
}

\author{
${ }^{1}$ Department of Infectious and Parasitic Diseases; ${ }^{2}$ Liver \\ Transplantation Division, Department of Surgery, University of \\ São Paulo Medical School; São Paulo, SP, Brazil
}

\begin{abstract}
Mycophenolate mofetil (MMF) is currently used for prophylaxis of acute rejection in solid organ transplantation. There have been diverging reports regarding an association between MMF and the risk of cytomegalovirus (CMV) infection. We reviewed the main published studies in an attempt to clarify the association between the use of MMF and the risk, frequency and severity of CMV infections. In a search of the Medline database with the terms "mycophenolate" and "cytomegalovir*", 42 articles were found to be relevant; among these, 29 articles were thoroughly analyzed. The first studies on MMF in renal transplantation already showed a tendency towards an association between this drug and the occurrence of CMV disease. Further studies were designed specifically to study this association; with the conclusion that an immunosuppressive regimen containing MMF increases the likelihood of CMV disease. Most studies were performed with kidney transplant recipients. We conclude that the use of MMF apparently increases the incidence of CMV disease in renal transplant patients; however, further studies are needed to confirm this association. Key Words: Mycophenolate mofetil, cytomegalovirus, transplant.
\end{abstract}

Mycophenolate mofetil (MMF) was isolated from the fungus Penicillium brevicompactum at the end of the $19^{\text {th }}$ century [1]. In the early 1970s, it was studied as a possible treatment for refractory psoriasis and cancer [1]. This drug was first introduced into clinical practice as an immunosuppressive agent in 1995, for the prevention and treatment of rejection episodes of organ transplant recipients. Recently, it has also been used for the treatment of autoimmune diseases [1].

Mycophenolate mofetil is a prodrug that is rapidly hydrolyzed by esterases in the intestine and in the blood into mycophenolic acid, which is the active component. It is a potent non-competitive and reversible inhibitor of inosine monophosphate dehydrogenase (IMPDH); it inhibits the de novo pathway of purine nucleotide synthesis, therefore depleting intracellular guanidine nucleotides [2]. Lymphocytes depend primarily on the synthesis of purine nucleotides, through a de novo pathway, different from neutrophils, which may also use the salvage pathway. Consequently, MMF has some specificity for $\mathrm{T}$ and $\mathrm{B}$ lymphocytes. Besides the activity against proliferation of lymphocytes, there is additional immunosuppressive activity via inhibition of glycosylation of adhesion molecules, thereby decreasing the recruitment of lymphocytes and monocytes to sites of graft rejection [2]. Finally, there is also inhibition of smooth muscle cell proliferation [3].

Received on 04 October 2005; revised 13 March 2006.

Address for correspondence: Dr. Edson Abdala. Av. Itaboraí, 311, Ap.24, Zip code: 04135-000 São Paulo - SP - Brazil.

E-mail: eabdala@uol.com.br

The Brazilian Journal of Infectious Diseases 2006;10(2):132-138. (C) 2006 by The Brazilian Journal of Infectious Diseases and Contexto Publishing. All rights reserved.
This drug is currently used for prophylaxis of acute rejection in renal, heart, lung, pancreas and liver transplants, along with calcineurin inhibitors, such as cyclosporine and tacrolimus, and with corticosteroids. During the past few years, its use in clinical practice has increased as a consequence of its confirmed efficacy and the possibility of dose reduction or suspension of calcineurin inhibitors, thus diminishing the incidence of adverse effects, such as nephrotoxicity due to tacrolimus [4].

Cytomegalovirus (CMV) infection is a major cause of morbidity in patients undergoing solid organ transplants [5]. Additionally, CMV has been found to be an independent risk factor for the development of other infectious complications, such as bacteremias, invasive fungal diseases and Epstein Barr virus (EBV)-related post-transplant lymphoproliferative disease; it is also a cause of acute and chronic allograft injury [5]. There is a hypothesis that cytomegalovirus may cause endothelial damage in the transplanted organ, leading to chronic transplant dysfunction [6].

In solid organ transplantation, primary infection by cytomegalovirus is mainly acquired when the donor is CMVseropositive and the recipient is CMV-seronegative ( $\mathrm{D}+/ \mathrm{R}-$ ), or else through blood products, though much less frequently [7]. Secondary infection is less frequent and occurs when there is reactivation of an endogenous virus, or through reinfection in a seropositive recipient [7]. CMV infection occurs mainly during the first three months following the transplant; but can be delayed in patients receiving CMV prophylaxis [5]. CMV infection is defined as evidence of CMV replication, regardless of symptoms [5]. CMV disease is a clinical expression of active infection, ranging from malaise, fever, myalgia, and arthralgia, to organ involvement, such as hepatitis, pneumonitis, gastroenteritis, colitis, and encephalitis [7]. 
Apart from the higher risk of CMV disease in the case of D+/R-, other risk factors for development of CMV disease include the type of transplant (lung, small intestine and pancreas transplant recipients are at the highest risk, while liver, heart and kidney recipients are at lower risk), and the recipient's state of immunosuppression, which depends on the immunosuppressive regimen used (use of antilymphocyte antibody therapy for rejection treatment is associated with higher risk), and host factors, such as age, co-morbidity, and neutropenia [5].

Two strategies are commonly used for CMV prevention: universal prophylaxis and preemptive therapy. Universal prophylaxis involves antiviral therapy for all "at-risk" recipients, for a defined period of time, beginning immediately post-transplant. In preemptive therapy, patients are monitored at regular intervals for early evidence of CMV replication by use of a laboratory assay, and if positive, they receive antiviral therapy before the onset of symptoms [5].

Conflicting data has been published regarding an association between MMF and the risk of CMV infection. We reviewed the principal published articles in an attempt to clarify the association between the use of MMF and the risk, frequency and severity of CMV infections.

\section{Methods}

Articles that contained the terms "mycophenolate" and "cytomegalovir*" were identified in a search of the Medline database, without limitations, resulting in 222 articles, up till June 2005. One hundred and sixty-eight articles were excluded because they did not include a comparison of incidence/ prevalence of CMV infection and use of MMF. Another five articles were excluded, as they were not published in English. Seven articles were excluded because the subjects were pediatric patients. Forty-two articles were considered relevant; among these, 29 original articles were thoroughly analyzed: three were the first studies to analyze the efficacy of MMF in renal transplant recipients; 14 were specifically designed to compare the association between MMF and CMV infections; 10 evaluated the efficacy of MMF, and two were renal transplant review articles.

The 29 articles were separated into three groups: the first group included the first articles whose main objective was to evaluate the efficacy of MMF; the second group included the articles which had as a primary goal an evaluation of the association between CMV infection and the use of MMF; the third group included the articles whose main objective was the analysis of the efficacy of the immunosuppressive drugs, and the occurrence of CMV was secondarily evaluated.

\section{Results}

First studies. Three major studies were performed to confirm the efficacy of mycophenolate mofetil as part of an immunosuppressive regimen for the prevention of acute rejection in renal transplants [8-10]. These studies were multicentric, prospective, randomized, controlled and doubleblinded. Data from these three studies suggested an increase in cytomegalovirus invasive tissue disease, compared to azathioprine or a placebo. The European Mycophenolate Mofetil Cooperative Study comprised 491 recipients of cadaveric renal allografts divided into three groups: all received cyclosporine and corticosteroids, and the three arms received a placebo, or 2 or $3 \mathrm{~g}$ of MMF. The incidence of invasive CMV disease was $2.4 \%, 3 \%$, and $6.9 \%$, respectively [8]. The second study, done by the Tricontinental Mycophenolate Mofetil Transplantation Study Groups, was performed with 503 patients, all of whom received cyclosporine and corticosteroids, and each arm received either azathioprine, or 2 or $3 \mathrm{~g}$ of MMF. The incidence of invasive CMV disease was $6 \%, 7 \%$ and $11 \%$, respectively, with predominance of gastrointestinal tract affection [9]. This study suggested that $2 \mathrm{~g} \mathrm{MMF/day} \mathrm{would} \mathrm{be} \mathrm{the} \mathrm{most} \mathrm{appropriate} \mathrm{dosage,} \mathrm{taking}$ into account the immunosuppressive effect and the risk of tissue invasion by CMV. In both papers, the incidence of CMV syndrome or CMV viremia was similar in all groups [8,9]. In the third study, by the US Renal Transplant Mycophenolate Mofetil Study Group [10], 499 patients received cyclosporine, corticosteroids and antithymocyte globulin, and were randomized to receive azathioprine, 2 or $3 \mathrm{~g}$ MMF. The donor/ recipient cytomegalovirus serological status was similar among the three treatment groups. MMF treatment resulted in greater incidence of tissue-invasive CMV than in the azathioprine group $(10.8 \%$ with $3 \mathrm{~g} /$ day and $9.1 \%$ with $2 \mathrm{~g} /$ day, versus $6.1 \%$ with azathioprine). None of the studies included statistical analysis. Their primary goal was to evaluate the outcome regarding acute rejection and not CMV infection. These were the initial studies that showed that there could be an association between the use of MMF and CMV disease, particularly in those patients receiving $3 \mathrm{~g} \mathrm{MMF} / \mathrm{d}$.

Studies designed to evaluate MMF x CMV. Fourteen articles evaluated the association between the use of MMF and the CMV infection/disease rates (Table 1).

Moreso et al. [11] compared three groups of renal transplant patients enrolled in the European Mycophenolate Mofetil Cooperative Study, treated with cyclosporine (target blood levels of $200-300 \mathrm{ng} / \mathrm{mL})$ and prednisone $(0.5 \mathrm{mg} / \mathrm{kg} / \mathrm{d}$ before surgery, gradually reduced to $0.1 \mathrm{mg} / \mathrm{kg} / \mathrm{d}$ in 3-6 months) and randomized to receive a placebo $(\mathrm{n}=27), 2 \mathrm{~g} \mathrm{MMF} / \mathrm{d}(\mathrm{n}=28)$, or $3 \mathrm{~g} \mathrm{MMF} / \mathrm{d}(\mathrm{n}=28)$, and a fourth group, which received $3 \mathrm{~g}$ $\mathrm{MMF} / \mathrm{d}$, with low doses of cyclosporine (target blood levels of $25-175 \mathrm{ng} / \mathrm{mL})$ and prednisone $(0.25 \mathrm{mg} / \mathrm{kg} / \mathrm{d}$, gradually reduced to $0.1 \mathrm{mg} / \mathrm{kg} / \mathrm{d}$ in 3 months). CMV disease was significantly increased in the $3 \mathrm{~g} \mathrm{MMF} / \mathrm{d}$ plus conventional doses of cyclosporine and prednisone $(35.7 \%$ versus $<8 \%$ in the other groups) group, suggesting that the reduction of immunosuppression by diminishing the doses of other 
Table 1. List of studies designed to evaluate the association between mycophenolate mofetil (MMF) and cytomegalovirus (CMV)

\begin{tabular}{|c|c|c|c|c|c|c|c|c|c|}
\hline Ref. & Organ & Study design & $\mathbf{N}$ & Arms & $\begin{array}{c}\text { CMV } \\
\text { prophylaxis/ }\end{array}$ & $\begin{array}{l}\text { CMV infection } \\
\text { preemptive } \\
\text { therapy }\end{array}$ & $\mathbf{P}$ & CMV disease & $\mathbf{P}$ \\
\hline 11 & kidney & $\begin{array}{l}\text { prospective, } \\
\text { randomized }\end{array}$ & 97 & $\begin{array}{l}\text { CYA + pred + placebo } \\
\text { CYA + pred + MMF 2g } \\
\text { CYA + pred + MMF 3g } \\
\text { CYA + pred (low doses) } \\
+ \text { MMF } 2 \mathrm{~g}\end{array}$ & $\mathrm{NI}$ & not evaluated & & $\begin{array}{c}3.7 \% \\
7.4 \% \\
35.7 \% \\
6.7 \%\end{array}$ & 0.002 \\
\hline 12 & kidney & prospective & 445 & $\begin{array}{l}\text { MMF } 2 \mathrm{~g}+\text { cort }(+ \text { anti- } \\
\text { lymphocyte + CYA }) \\
\text { AZA + cort + ATG + CYA }\end{array}$ & No & not evaluated & & $\begin{array}{l}24.6 \% \\
21.6 \%\end{array}$ & NI \\
\hline 13 & kidney & prospective & 158 & $\begin{array}{l}\mathrm{CYA}+\text { pred + MMF 2g } \\
\mathrm{CYA}+\text { pred + AZA + ATG }\end{array}$ & Yes & not evaluated & $9.5 \%$ & $29 \%$ & 0.005 \\
\hline 14 & kidney & case-control & 741 & $\begin{array}{l}\mathrm{CYA}+\text { cort } \\
\mathrm{CYA}+\mathrm{AZA}+\text { cort } \\
\mathrm{CYA}+\mathrm{AZA}+\text { cort + ATG } \\
\mathrm{CYA}+\mathrm{MMF}+\text { cort } \\
\text { tacrolimus + AZA + cort } \\
\text { tacrolimus + MMF + cort } \\
\mathrm{CYA}+\text { rapamycin + cort }\end{array}$ & No & not evaluated & & $\begin{array}{l}\text { tacrolimus }+ \\
\text { MMF }+ \text { cort } \\
\text { OR }=3.065, \\
\text { CI }=1.817-5.169\end{array}$ & 0.0063 \\
\hline 15 & kidney & case-control & 136 & $\begin{array}{l}\text { CYA + pred + MMF 2g } \\
\text { CYA + pred + AZA }\end{array}$ & $\mathrm{NI}$ & not evaluated & & no difference & 0.958 \\
\hline 17 & kidney & retrospective & 84 & $\begin{array}{l}\mathrm{CYA}+\text { cort }+\mathrm{MMF} \\
\text { (median } 2.6 \mathrm{~g})\end{array}$ & no & analysis along & 7 & $67 \%$ & $<0.05$ \\
\hline 18 & kidney & retrospective & 1018 & $\begin{array}{l}\mathrm{CYA}+\text { cort } \\
\text { regimen with } \mathrm{MMF} \\
\text { regimen without } \mathrm{MMF}\end{array}$ & NI & $\begin{array}{l}\text { with CMV disease } \\
\text { analysis along } \\
\text { with CMV disease }\end{array}$ & $\begin{array}{l}30 \% \\
3.6 \%\end{array}$ & $8.4 \%$ & $<0.01$ \\
\hline 19 & kidney & retrospective & 280 & $\begin{array}{l}\mathrm{CYA}+\text { pred + MMF } \\
\mathrm{CYA}+\text { pred + AZA }\end{array}$ & $\mathrm{NI}$ & not evaluated & & $\begin{array}{l}1 \text { episode/ } \\
18 \text { treatment mo } \\
1 \text { episode/ } \\
346 \text { treatment mo }\end{array}$ & $<0.01$ \\
\hline 20 & kidney & retrospective & 66 & $\begin{array}{l}\text { tacrolimus }+ \text { cort }+ \\
\text { MMF } 2 \mathrm{~g} \\
\text { tacrolimus }+ \text { cort }+ \text { AZA }\end{array}$ & NI & $\begin{array}{l}11.4 \% \\
\text { none }\end{array}$ & 0.10 & not evaluated & \\
\hline 21 & kidney & retrospective & 91 & $\begin{array}{l}\mathrm{CYA}+\text { pred + } \\
\mathrm{MMF} 1.5-2 \mathrm{~g} \\
\mathrm{CYA}+\text { pred }+\mathrm{AZA}\end{array}$ & yes & $\begin{array}{l}\text { analysis along } \\
\text { with CMV disease }\end{array}$ & fu & $\begin{array}{l}22 \%(\mathrm{CMV} / \\
\text { ungal infection) }\end{array}$ & NI \\
\hline 6 & kidney & retrospective & 470 & $\begin{array}{l}\mathrm{MMF}+\mathrm{CYA}+\text { cort } \\
\text { CYA (microemulsion) + cort } \\
\text { CYA (standard) + cort }\end{array}$ & $\begin{array}{l}\text { yes } \\
53 \%\end{array}$ & $\begin{array}{l}64 \% \\
35 \%\end{array}$ & 0.041 & 1 not evaluated & \\
\hline 16 & kidney & $\begin{array}{l}\text { retrospective, } \\
\text { descriptive }\end{array}$ & 29 & $\begin{array}{l}\mathrm{CYA}+\text { pred + MMF } 2 \mathrm{~g} \\
\mathrm{CYA}+\text { pred }+\mathrm{AZA}\end{array}$ & yes & not evaluated & & $\begin{array}{l}58 \% \\
18 \%\end{array}$ & 0.03 \\
\hline 22 & liver & $\begin{array}{l}\text { prospective, } \\
\text { randomized }\end{array}$ & 63 & $\begin{array}{l}\text { CYA + cort + anti- } \\
\text { lymphocyte + MMF 1.5-2g } \\
\text { CYA + cort + anti-lymphocyte }\end{array}$ & $\begin{array}{c}\text { yes } \\
\text { te }+ \text { AZA }\end{array}$ & no difference & NI & not evaluated & \\
\hline 23 & liver & prospective & 157 & $\begin{array}{l}\text { tacrolimus }+ \text { cort } \\
\text { tacrolimus }+ \text { cort }+ \text { MMF } 2 g\end{array}$ & yes & no difference & & no difference & $>0.20$ \\
\hline
\end{tabular}

$\mathrm{NA}=$ not applicable; NS = non-significant; pred = prednisone; cort $=$ corticosteroids .

$\mathrm{NI}=$ not informed; $\mathrm{AZA}=$ azathioprine CYA = cyclosporine . 
immunosuppressive drugs along with $3 \mathrm{~g} \mathrm{MMF/d} \mathrm{reduces} \mathrm{the}$ incidence of CMV disease, without affecting rejection rates. Moreover, the incidence of CMV disease in patients treated with 3g MMF/d (7.4\%), and reduced cyclosporine and prednisone doses was similar to the incidence in patients receiving $2 \mathrm{~g} \mathrm{MMF/d}$ and conventional cyclosporine and prednisone doses $(6.7 \%)$. The CMV serological status was similar among the groups, but CMV prophylaxis was not reported.

A prospective trial by Giral et al. [12] compared 445 renal transplant patients who were treated with either MMF $2 \mathrm{~g} / \mathrm{d}$ $(\mathrm{n}=126)$ or azathioprine $(\mathrm{n}=319)$ (along with corticosteroids and anti-thymocyte globulin (ATG) as induction therapy, followed by cyclosporine). None were treated with preemptive or prophylactic gancyclovir, and CMV seropositivity of donor/ recipient was not informed. The incidence of CMV disease was similar in the two groups (24.6\% in the MMF group versus $21.6 \%$ in the Aza group); however, after treatment with gancyclovir for 14 days, graft survival increased significantly by up to one year in the patients in the MMF group, compared with those in the azathioprine group (90\% versus $77 \%$, respectively, $\mathrm{p}<0.02)$. Apparently, gancyclovir had better antiviral efficacy when associated with MMF, resulting in protection against the deleterious effects of CMV on allografts and against other consequences, such as graft dysfunction.

Another prospective study by Bernabeu-Wittel [13], made in Spain with renal transplant recipients, compared two groups that received cyclosporine and prednisone, combined with either $2 \mathrm{~g} \mathrm{MMF} / \mathrm{d}(\mathrm{n}=76)$ or azathioprine and antilymphocyte globulin (7-14 days, $n=82$ ), analyzed infectious complications during the first six months post-transplantation. Patients at high-risk for CMV infection (D+/R- and use of OKT3) received a course of anti-CMV immunoglobulin. Even though there were similar proportions of CMV seronegative recipient/CMV seropositive donor, the incidence of CMV disease was significantly higher in the MMF cohort than in the azathioprine-ATG cohort (29\% versus $9.5 \%$, respectively, $\mathrm{p}=0.005$ ). The upper gastrointestinal tract was the most affected organ. In the multivariate analysis, with serostatus D+/R-, treatment with mycophenolate, and acute rejection episodes were independently associated with higher risk of developing CMV disease.

Immunosuppressive regimens were compared and analyzed in a case-control study on the development of tissue-invasive CMV infection in 741 renal transplant recipients [14]. There were 101 patients (13.6\%) with CMV disease, with a total of 125 episodes. Seven basic drug regimens were identified; based on multivariate analysis, it was found that previous acute rejection treatment was a risk factor for developing CMV disease, as was an immunosuppressive drug regimen consisting of tacrolimus, MMF and steroids (odds ratio (OR) $=3.065$, confidence interval $(\mathrm{CI})=1.817-5.169, \mathrm{p}=0.0063$ ). Also, the use of MMF did not influence the likelihood of developing gastrointestinal CMV disease. The protocols that used tacrolimus, azathioprine and steroids or cyclosporine, MMF and steroids were not found to be significant independent factors for the occurrence of CMV.

Sarmiento et al. designed a case-control study in 1998 [15] with renal transplant recipients, with three controls for each of the 34 cases of CMV infection/disease. After logistic regression, the significant risk factors for $\mathrm{CMV}$ were proof of past rejection episodes and positive CMV donor status. No association was found between MMF $(2 \mathrm{~g} / \mathrm{d})$ and CMV infection. In 2000, Sarmiento et al. analyzed 29 renal transplant recipients who developed CMV disease, and found that MMF was part of the immunosuppressive regimen used in 58\% of the patients with organ involvement, versus azathioprine in $18 \%(\mathrm{p}=0.03)$ [16]. The median number of organs involved was significantly greater in the MMF group than in the azathioprine group ( 2 versus $1, \mathrm{p}=0.015$ ). All patients received post-transplant prophylaxis with $200 \mathrm{mg}$ acyclovir three times a day (tid) for 21 days. The frequency of CMV D+/R- was similar in the two groups. The small number of patients limits conclusions, as does the lack of controls.

Ter Meulen et al. [17] performed a retrospective analysis of 84 renal transplant recipients, in which all cases were donor CMV seropositive and recipient CMV seronegative. The objective was to determine if the addition of MMF (median $2.6 \mathrm{~g} /$ day) to a regimen containing cyclosporine and prednisone would increase the frequency and/or severity of primary CMV infection in this high-risk population; no patients had received any prophylaxis for CMV. Baseline characteristics of the two groups differed only in age: the MMF group was significantly (seven years) older than the control group. Primary CMV infection, detected by IgG seroconversion, was similar in the two groups. However, CMV disease was more prevalent in the MMF group than in the control group (67\% versus $30 \%$, respectively, $\mathrm{p}<0.05$ ). Although there was a tendency towards increased use of anti-T-cell therapy for treatment of acute rejections in the MMF group, the conclusions were not altered, when the patients treated with anti-T-cell therapy were excluded. In addition, the two groups had similar severity of disease, frequency of invasive tissue disease and post-transplantation time until the manifestation of symptoms (in $90 \%$ of the patients, the first symptoms developed within three months after the transplant).

A Spanish study analyzed the use of MMF and the incidence of CMV infection in 1,018 renal transplants; $8.4 \%$ of 381 patients receiving MMF had CMV infections, compared to $3.6 \%$ of 637 patients without MMF ( $\mathrm{p}<0.01)$ [18]. The frequency of CMV D+/R- and treatment with OKT3 were similar in the two groups. Neither the MMF dosages nor CMV prophylaxis were reported.

In a Croatian study [19], 280 kidney transplant recipients were treated with azathioprine, cyclosporine and steroids, or azathioprine and steroids, while 219 transplant patients were treated with either MMF (dose not specified), cyclosporine and steroids, or MMF and steroids. There were no differences in donor-recipient CMV serological status. The AZA group 
had 51 CMV disease episodes (one episode per 346.5 treatment months), while the MMF group experienced 43 episodes (one episode per 118.1 treatment months) ( $p<0.01)$. The mean time till onset of disease was also different: median 4 months for the AZA group, and 1.8 months for MMF group. There were five cases of CMV pneumonitis in the AZA group, with a mortality rate of $80 \%$; only one patient in the MMF group had CMV pneumonitis.

Satoh et al. [20] retrospectively compared two treatment regimens following renal transplant, consisting of tacrolimus and steroids, with either azathioprine $(n=22)$ or $2 \mathrm{~g} \mathrm{MMF} / \mathrm{d}$ $(n=44)$. D+/R- cases were excluded from the study. The incidence of CMV infection in the MMF group was $11.4 \%$, versus zero in the AZA group.

A study performed on geriatric (age $>60$ years) renal transplant patients [21] retrospectively compared a cohort of 46 patients treated with AZA, prednisone and cyclosporine with a cohort of 45 patients treated with MMF $(1.5-2 \mathrm{~g} / \mathrm{d})$, prednisone and cyclosporine. Intravenous gancyclovir was administered to the patients during antibody administration, and acyclovir was given to all patients for the first six months after transplantation. Diagnosis of CMV was made with clinical presentation and one of the following: four-fold increase in IgG titers, new seroconversion, or direct immunohistochemical staining of tissue. The two groups were similar regarding antibody therapy and preoperative CMV serologic status. Infectious complications were evaluated during one year after transplantation. Fungal and CMV infections were analyzed together. The diagnostic methods for CMV had low sensitivity. The incidence was higher in the MMF group (22\% versus $11 \%$ in the AZA group). MMF was demonstrated as the only independent risk factor for the development of CMV and fungal infection (RR 3.8, CI 1.5-9.8).

In a study by de Maar et al. [6], 470 renal transplant recipients were retrospectively evaluated according to the immunosuppressive regimen used: cyclosporine (standard formulation) and prednisolone, versus cyclosporine (microemulsion formulation) and prednisolone, versus $\mathrm{MMF}$ and cyclosporine and prednisolone. Patients who received induction therapy with OKT3 or ATG were excluded, and gancyclovir was given preemptively. The MMF dosage was not informed. The incidence of CMV infection was $35 \%$ in the first group, 53\% in the second group, and 64\% in the third group. There were no significant differences between the second and third groups, suggesting that the introduction of the microemulsion formulation of cyclosporine was mainly responsible for the increase in CMV infection, and not MMF. However, there was a significant difference in the duration of infection (prolonged viremia with MMF). No invasive disease was found, probably due to preemptive treatment. These results are difficult to evaluate, as the study comprises a large period (1989-1998), during which there were many different therapeutic approaches. In addition, there was no information regarding cyclosporine blood levels.
In another trial [22], 63 recipients of a complete or right lobe split liver graft were prospectively randomized to receive AZA or 1.5-2g MMF/d, as part of an immunosuppressive regimen containing lymphocyte antibodies, corticosteroids, and cyclosporine. Gancyclovir was given preemptively, and information on CMV serological was not given. No significant differences were found in the incidence of CMV infection.

In a study performed by Paterson et al. [23], liver transplant recipients who developed neurotoxicity or nephrotoxicity, supposedly due to tacrolimus, had their doses of this drug lowered (5-10) and they started using $2 \mathrm{~g} \mathrm{MMF/d.} \mathrm{Preemptive}$ CMV therapy was also implemented. Out of 157 patients, 46 had their immunosuppressive regimen altered by the time of observation (16 in the first month, five from 1-5 months after transplant, and $25>6$ months after transplant). After six months of observation, no significant differences were found in the occurrence of cytomegalovirus infection or disease, when compared to patients not treated with MMF. Patients who had the regimen changed more than six months post-transplant were grouped along with those without change, as the analysis was made during the six months after transplant.

Finally, renal transplant recipients in the United States Renal Data System were analyzed in a historical cohort study of patients with a primary discharge diagnosis of CMV disease during a three-year period [24]. Of 33,479 recipients of renal transplants, 695 patients were hospitalized for CMV disease. Controlled for potential confounders (such as CMV serology and rejection), the use of mycophenolate mofetil was found to be a risk factor, based on univariate and multivariate analysis. A systematic review evaluated the safety of MMF versus azathioprine in renal transplantation, and identified 20 trials, including a total of 6,387 patients [25]. The incidence of CMV infection was higher with $3 \mathrm{~g} M M F$ compared to azathioprine; there were no significant differences between $2 \mathrm{~g} M M F$ and azathioprine or between $2 \mathrm{~g}$ and $3 \mathrm{~g}$ MMF.

Studies designed to evaluate the efficacy of MMF. Seven articles compared immunosuppressive regimens, with or without MMF, for renal allograft recipients for the prevention of acute rejection. Higher rates of CMV infection or disease were found in four of them (three retrospective and one prospective) [26-29]. In two studies, there was no differences in CMV infection frequencies; although in one study there was a non-significant increase [30,31]. Another study [32] was conducted to examine the association between MMF and chronic allograft nephropathy; CMV infection and disease was more frequent in the azathioprine group. However, this group received more antirejection therapy.

A randomized trial of cardiac recipients was performed [33], comparing $3 \mathrm{~g}$ mycophenolate versus azathioprine; CMV disease was more invasive in MMF patients, with similar rates of CMV infection. Eckhoff et al. [34] performed a study of liver transplantation, in which there were similar rates of CMV infection among patients receiving tacrolimus versus 
tacrolimus plus 2g MMF. Lastly, a randomized multicentric trial of $2 \mathrm{~g}$ MMF versus azathioprine treatment of lung transplant recipients [35] revealed similar rates of CMV infection.

\section{Conclusions}

The first studies of MMF had already shown a tendency towards an association between this drug and CMV disease. Based on further studies especially designed to evaluate this association, an immunosuppressive regimen containing MMF apparently increases the likelihood of CMV disease. However, it is not clear whether it is the drug itself or the global immunosuppression caused by an association of multiple immunosuppressive drugs that causes such an increase. Data from the study by Moreso et al. [11] suggest that it is the degree of immunosuppression that determines the increased risk of CMV infection, and not the drug itself. However, Ter Meulen et al. [17] argue that the use of MMF is not accompanied by an increase in bacterial or fungal infections, which goes against the idea that general attenuation of the immune response is the sole factor responsible for the increased incidence of CMV disease. It is then suggested that MMF induces a specific change in the primary immune response to CMV infections, which more frequently leads to symptomatic CMV disease.

We found that most of the studies published on this subject were performed with renal transplant recipients, making it difficult to reach conclusions regarding other solid organ transplants. The two prospective studies on liver recipients that we reviewed did not show any difference in the incidence of CMV infection. Furthermore, unfortunately, most studies were done with patients with a cyclosporine-based immunosuppressive regimen. However, tacrolimus is currently the most commonly used calcineurin inhibitor.

We conclude that the use of MMF increases the incidence of CMV disease in renal transplant patients, though further studies are needed to confirm this association.

\section{Acknowledgements}

The authors thank Aurea Aparecida Silva Garibaldi for helping with the preparation of this manuscript.

\section{References}

1. Gallagher H., Andrews P.A. Cytomegalovirus infection and abdominal pain with mycophenolate mofetil - is there a link? Drug Saf 2001;24:405-12.

2. Allison A.C., Eugui E.M. Purine metabolism and immunosuppressive effects of mycophenolate mofetil (MMF). Clin Transplant 1996;10:77-84.

3. Wang K., Zhang H., Li Y., et al. Safety of mycophenolate mofetil versus azathioprine in renal transplantation: a systematic review. Transplant Proc 2004;36:2068-2070.
4. Kreis H. New strategies to reduce nephrotoxicity. Transplantation 2001;72: S99-104.

5. Anon. Cytomegalovirus. Am J Transplant 2004;4 Suppl10:51-58.

6. de Maar E.F., Verschuuren E.A.M., Homan vd Heide J.J., et al. Effects of changing immunosuppressive regimen on the incidence, duration, and viral load of cytomegalovirus infection in renal transplantation: a single center report. Transpl Infect Dis 2002; 4: 17-24.

7. van der Bij W., Speich R. Management of Cytomegalovirus Infection and Disease after Solid-Organ Transplantation. Clin Infect Dis 2001;33(Suppl1):S33-7.

8. European Mycophenolate Mofetil Cooperative Study Group. Placebo-controlled study of mycophenolate mofetil combined with cyclosporine and corticosteroids for prevention of acute rejection. Lancet 1995;345:1321-5.

9. Tricontinental Mycophenolate Mofetil Transplantation Study Group. A blinded, randomized clinical trial of mycophenolate mofetil for the prevention of acute rejection in cadaveric renal transplantation. Transplantation 1996; 61:1029-37.

10. Sollinger H.W., US Renal Transplant Mycophenolate Mofetil Study Group. Mycophenolate mofetil in cadaveric renal transplantation. Am J Kidney Dis 1995;60:225-32.

11. Moreso F., Séron D., Morales J.M., Cruzado J.M., et al. Incidence of leucopenia and cytomegalovirus disease in kidney transplants treated with mycophenolate mofetil combined with low cyclosporine and steroid doses. Clin Transplant 1998; 12:198-205.

12. Giral M., Nguyen J.M., Daguin P., et al. Mycophenolate Mofetil does not modify the incidence of cytomegalovirus (CMV) disease after kidney transplantation but prevents CMV-induced chronic graft dysfunction. J Am Soc Nephrol 2001;12:1758-63.

13. Bernabeu-Wittel M., Naranjo M., Cisneros J.M., et al. Infections in renal transplant recipients receiving mycophenolate versus azathioprine-based immunosuppression. Eur J Clin Microbiol Infect Dis 2002;21:173-80.

14. Kuypers D.R.J., Maes B.D., Coosemans W., Pirenne J, et al. Role of immunosuppressive drugs in the development of tissue-invasive cytomegalovirus infection in renal transplant recipients. Transplant Proc 2002;34:1164-70.

15. Sarmiento J.M., Munn S.R., Paya C.V., et al. Is cytomegalovirus infection related to mycophenolate mofetil after kidney transplantation?: A case-control study. Clin Transplant 1998; 12:371-4.

16. Sarmiento J.M., Dockrell D.H., Schwab T.R., et al. Mycophenolate mofetil increases cytomegalovirus invasive organ disease in renal transplant patients. Clin Transplant 2000; 14 : 136-8.

17. Ter Meulen C.G., Wetzels J.F.M., Hilbrands L.B. The influence of mycophenolate mofetil on the incidence and severity of primary cytomegalovirus infections and disease after renal transplantation. Nephrol Dial Transplant 2000; 15:711-4.

18. Muñoz M.A., Andrés A., Gallego R., et al. Mycophenolate Mofetil Immunosuppressive Therapies Increase the Incidence of Cytomegalovirus Infection in Renal Transplantation. Transplant Proc 2002;34:97.

19. Basic-Jukic N., Kes P., Bubic-Filipi L.J., et al. Does mycophenolate mofetil increase the incidence of cytomegalovirus disease compared with azathioprine after cadaveric kidney transplantation? Transplant Proc 2005;37:850-1. 
20. Satoh S., Tada H., Murakami M., et al. The influence of mycophenolate mofetil versus azathioprine and mycophenolic acid pharmacokinetics on the incidence of acute refection and infectious complications after renal transplantation. Transplant Proc 2005;37:1751-3.

21. Meier-Kriesche H., Friedman G., Jacobs M., et al. Infectious complications in geriatric renal transplant patients: comparison of two immunosuppressive protocols. Transplantation 1999;68:1496-1502.

22. Fischer L., Sterneck M., Gahlemann C.G., et al. A prospective study comparing safety and efficacy of mycophenolate mofetil versus azathioprine in primary liver transplant recipients. Transplant Proc 2000;32:2125-7.

23. Paterson D., Singh N., Panebianco A., et al. Infectious complications occurring in liver transplant recipients receiving mycophenolate mofetil. Transplantation 1998; $66: 593-8$.

24. Abbott K.C., Hypolite I.O., Viola R., et al. Hospitalizations for cytomegalovirus diseases after renal transplantation in the United States. Ann Epidemiol 2002;12:402-9.

25. Wang K., Zhang H., Li Y., et al. Safety of mycophenolate mofetil versus azathioprine in renal transplantation: a systematic review. Transplant Proc 2004; 36:2068-70.

26. Vítko S., Margreiter R., Weimar W., et al, RAD B201 Study Group. Everolimus (Certican) 12-month safety and efficacy versus mycophenolate mofetil in de novo renal transplant recipients. Transplantation 2004;78:1532-40.

27. Roth D., Colona J., Burke G.W., et al. Primary immunosuppression with tacrolimus and mycophenolate mofetil for renal allograft recipients. Clin Transplant 1998; 65:248-52.
28. Miladipour A.H., Ghods A.J., Nejadgashti H. Effect of mycophenolate mofetil on the prevention of acute renal allograft rejection. Transplant Proc 2002;34:2089-90.

29. Karakayali H., Yagmurdur M.C., Emiroglu R., et al. Effects of mycophenolate mofetil on the gastrointestinal system and kidney graft function: early experience at one center. Transplant Proc 2002;34:2093-5.

30. Joh J.W., Lee H.H., Lee D.S., et al. The influence of mycophenolate mofetil and azathioprine on the same cadaveric donor renal transplantation. J Korean Med Sci 2005;20:79-81.

31. Shapiro R., Jordan M.L., Scantlebury V.P., et al. A prospective, randomized trial of tacrolimus/prednisone versus tacrolimus/ prednisone/mycophenolate mofetil in renal transplant recipients. Transplantation 1999;67:411-5.

32. Merville P., Bergé F., Deminière C., et al. Lower incidence of chronic allograft nephropathy at 1 year post-transplantation in patients treated with mycophenolate mofetil. Am J Transnplat 2004;4:1769-75.

33. Eisen H.J., Kobashigawa J., Keogh A., et al, Mycophenolate Mofetil Cardiac Study Investigators. Three-year results of a randomized, double-blind, controlled trial of mycophenolate mofetil versus azathioprine in cardiac transplant recipients. J Heart Lung Transplant 2005;24:517-25.

34. Eckhoff D.E., McGuire B.M., Frenette L.R., et al. Tacrolimus (FK506) and mycophenolate mofetil combination therapy versus tacrolimus in adult liver transplantation. Transplantation 1995;65:180-7.

35. Palmer S.M., Baz M.A., Sanders L., et al. Results of a randomized, prospective, multicenter trial of mycophenolate mofetil versus azathioprine in the prevention of acute lung allograft rejection. Transplantation 2001;71:1772-6. 